\section{BMJ Open Respiratory Research}

\title{
Communication of a mesothelioma diagnosis: developing recommendations to improve the patient experience
}

\author{
Bethany Hope Taylor, ${ }^{\oplus 1}$ Clare Warnock, ${ }^{2}$ Angela Tod ${ }^{1}$
}

To cite: Taylor BH, Warnock C, Tod A. Communication of a mesothelioma diagnosis: developing recommendations to improve the patient experience. BMJ Open Resp Res

2019;6:e000413. doi:10.1136/ bmjresp-2019-000413

Received 25 January 2019 Revised 11 March 2019

\section{Check for updates}

(c) Author(s) (or their employer(s)) 2019. Re-use permitted under CC BY-NC. No commercial re-use. See rights and permissions. Published by BMJ.

${ }^{1}$ School of Nursing and Midwifery, University of Sheffield, Sheffield, UK ${ }^{2}$ Sheffield Teaching Hospitals NHS Foundation Trust, Sheffield, UK

Correspondence to Dr Bethany Hope Taylor; btaylor3@sheffield.ac.uk

\section{ABSTRACT}

Background Malignant pleural mesothelioma (MPM) is an aggressive cancer linked to asbestos exposure and inhalation. As with other cancers, receiving a diagnosis of MPM is challenging and distressing. Particular challenges are associated with communicating a diagnosis of MPM, including explaining the disease and its prognosis, treatment options and legal and financial implications. Receiving A Diagnosis Of Mesothelioma (RADIO Meso) aimed to understand the experience of communicating a diagnosis of MPM from the perspective of patients, family carers and health professionals.

Methods This qualitative study comprised 31 individual interviews with patients, family carers and health professionals. This was followed by two group interviews $(n=42)$ and an electronic consultation exercise $(n=39)$. Results This study provides unique insight into the mesothelioma diagnostic experience of patients, family carers and health professionals. Key findings include the importance of regarding diagnosis as a process, and provision of continuity and consistency. The clinical nurse specialist and effective multidisciplinary team working provided vital contributions to successful mesothelioma diagnostic communication. Facilitators to diagnostic communication included honesty and timeliness in communication, partnership working and maintaining a patient-centred approach. Challenges to enhancing mesothelioma diagnosis communication included accessing ongoing training, ensuring a suitable clinical environment and being able to allocate appropriate time. Conclusion The RADIO Meso study highlights factors that influence the communication of a diagnosis of MPM from the perspectives of individual patients and family carers. These findings provide the basis for a set of recommendations that can be used by health professionals to improve the MPM diagnostic experience.

\section{INTRODUCTION}

Malignant pleural mesothelioma (MPM) is an aggressive cancer linked to asbestos exposure and inhalation. The UK has among the highest incidence with over 2700 new cases a year. ${ }^{1}$ Innovative medical, surgical and radiotherapy approaches are emerging to improve length and quality of life; however, there are currently no curative treatments for MPM. In England, overall median survival is 9.5
Key messages

What is the experience of communicating a diagnosis of malignant pleural mesothelioma from the perspective of patients, family carers and health professionals?

- Successfully communicating a diagnosis of mesothelioma relies on a complex balance of factors including consistency and continuity, honesty, environment, resources and training. Access to a specialist nurse and being patient-centred facilitated diagnostic communication.

$>$ Getting the communication of a diagnosis of mesothelioma right can have an enduring impact on patient experience across the pathway.

months. One-year and 3-year survival are 38\% and $7 \%$ respectively. ${ }^{2}$

Receiving a diagnosis of cancer is distressing; however, a recent literature review indicated that there are particular challenges associated with communicating a diagnosis of MPM. ${ }^{3}$ These challenges relate to explaining the diagnosis and prognosis, treatment options and legal and financial implications. The shock of receiving an MPM diagnosis can lead to poor psychological and social outcomes, including anxiety, depression and anger. ${ }^{45}$ Patients have reported that a predominant memory of diagnosis was one of hopelessness due to its incurable nature and lack of treatment options. ${ }^{6}$ Balancing realistic expectations with hope and knowing how to share the information with their family have also been identified as difficult experiences to navigate during the diagnostic period. ${ }^{7}$ MPM has a latency period reported to be between 20 and 50 years. This long period of time from asbestos exposure to disease can also add to the struggle to understand the MPM diagnosis.

Breaking bad news (BBN), such as communicating a diagnosis of MPM, is a complex and highly skilled activity. ${ }^{8}$ If done badly, it can impact on subsequent quality of life and wellbeing. ${ }^{9}$ Recent research indicated that considering $\mathrm{BBN}$ as a process involving multiple 
episodes of information provision and supportive interventions is a useful approach and can facilitate good practice. ${ }^{10}{ }^{11}$ This is in comparison to emphasising the single episode of care when bad news, such as a diagnosis, is confirmed. In this paper, when we refer to communicating a diagnosis or diagnostic experience, we include the period of consultations, tests and procedures leading up to diagnosis, as well as the time after diagnosis when people are coming to terms with their condition and developing an understanding of it.

Despite the profound impact of receiving a MPM diagnosis, and the imperative for this communication to be conducted effectively, there has been little research to illuminate experience and inform practice. The

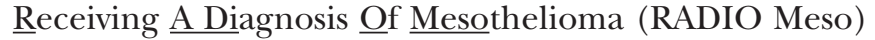
study was conducted to address this evidence gap. Using qualitative methods, RADIO Meso aimed to understand the experience of communicating a diagnosis of MPM from the perspective of patients, family carers and health professionals. These findings were then used to develop a set of recommendations to improve the MPM diagnostic experience. This paper presents the key findings from RADIO Meso that informed those recommendations.

\section{METHODS}

This qualitative study comprised individual and group interviews, followed by a consultation exercise conducted electronically.

\section{Sampling and recruitment \\ Individual interviews}

This study gathered the diagnostic experiences, perceptions and understandings of patients, family carers and health professionals. Purposive sampling was used to identify individual participants for interview. This enabled the recruitment of a range of patients and carers in terms of age, gender, time since diagnosis and treatment centre.

Eligible participants included a person, or family carer of someone, who:

- Had received a diagnosis of mesothelioma between 3 and 12 months ago.

- Was not experiencing physical or emotional distress that would be aggravated by participation.

- Was able to give informed consent.

- Spoke English.

- Was able to and wanted to share their experiences of diagnosis.

Patients and family carers were recruited differently to the health professional participants of RADIO Meso. This was to prevent potential bias that could occur if we recruited nurses and patients from the same hospital.

People with a mesothelioma diagnosis and family carers were invited to take part in an individual interview via study information circulated by Mesothelioma UK. Information was sent in mailshots,social media and newsletters. People were asked to contact the Mesothelioma UK helpline if interested in participating. Helpline staff

\begin{tabular}{ll}
\hline \multicolumn{2}{l}{$\begin{array}{l}\text { Table 1 RADIO Meso patient and carer interview } \\
\text { participants }\end{array}$} \\
\hline Participant ID & Participant details \\
\hline Patient 1 & Man with mesothelioma \\
\hline Patient 2 & Woman with mesothelioma \\
\hline Patient 3 & Woman with mesothelioma \\
\hline Patient 4 & Woman with mesothelioma \\
\hline Patient 5 & Man with mesothelioma \\
\hline Patient 6 & Man with mesothelioma \\
\hline Family carer 1 & Daughter of man with mesothelioma \\
\hline Family carer 2 & Daughter of a man with mesothelioma \\
\hline Family carer 3 & Daughter of a man with mesothelioma \\
\hline Family carer 4 & Wife of a man with mesothelioma \\
\hline Family carer 5 & Daughter of a man with mesothelioma \\
\hline Family carer 6 & Daughter of a man with mesothelioma \\
\hline Family carer 7 & Wife of a man with mesothelioma \\
\hline Family carer 8 & Wife of a man with mesothelioma \\
\hline Family carer 9 & Daughter of a man with mesothelioma \\
\hline
\end{tabular}

RADIO Meso, Receiving A Diagnosis Of Mesothelioma.

discussed the study and liaised with the research team if people were happy to participate. The interview sample comprised six patients (three men and three women), nine family carers (six daughters and three female partners of patients) (table 1).

Recruitment of health professionals was conducted differently. To recruit health professionals, study information and invitations to participate were sent by email to members of the National Lung Cancer Forum for Nurses (NLCFN) and the British Thoracic Oncology Group. Lung cancer nurse specialist (LCNS) recruited from NLCFN formed the majority of individual interview staff participants $(n=14)$. We did not recruit Mesothelioma clinical nurse specialists (CNSs). At the time of the study, there were 15 Mesothelioma CNSs in the UK supported by and linked to Mesothelioma UK. There are now 24. For most of the UK, people with mesothelioma form part of a LCNS caseload and do not have access to a Mesothelioma CNS. By recruiting LCNSs through NLCFN, our sample reflected service provision in most of the UK, and ensured the inclusion of those working in a range of settings with a range of experience. Unfortunately, despite a reminder recruitment email, only one doctor was recruited. This limits the extent of the doctors data included in the sample. However, the one interview was included to enable the integration of some medical experience.

In all, $14 \mathrm{CNSs}$, one doctor and one support worker (table 2) are interviewed.

\section{Group interviews}

The group interviews aimed to test and expand on findings from the individual interviews and move towards 


\section{Table 2 RADIO Meso staff interview participants}

\begin{tabular}{|c|c|}
\hline $\begin{array}{l}\text { Participant } \\
\text { ID }\end{array}$ & Participant details \\
\hline LCNS 1 & $\begin{array}{l}\text { In a team of } 2 \text { LCNSs at an NHS Hospital Trust } \\
\text { in a town. In post } 3 \text { years. }\end{array}$ \\
\hline LCNS 2 & $\begin{array}{l}\text { Single-handed LCNS in large NHS Hospital } \\
\text { Trust in a city. Just awarded funding for } \\
\text { additional LCNS post. In post } 12 \text { years. }\end{array}$ \\
\hline LCNS 3 & $\begin{array}{l}\text { One of three LCNS in the team in an NHS } \\
\text { Hospital Trust serving rural/town area. In post } \\
3 \text { years }\end{array}$ \\
\hline LCNS 4 & $\begin{array}{l}\text { One of three LCNS in the team in an NHS } \\
\text { Hospital Trust serving rural/town area. In post } \\
12 \text { months. }\end{array}$ \\
\hline LCNS 5 & $\begin{array}{l}\text { One of two LCNS in the team in an NHS } \\
\text { Hospital Trust serving rural/town area. In post } \\
\text { over } 18 \text { years. }\end{array}$ \\
\hline LCNS 6 & $\begin{array}{l}\text { Single-handed LCNS in an NHS Hospital Trust } \\
\text { serving sea side town. In post } 3 \text { years. }\end{array}$ \\
\hline LCNS 7 & $\begin{array}{l}\text { Single-handed LCNS in an NHS Hospital Trust } \\
\text { serving rural area. In post } 17 \text { years. }\end{array}$ \\
\hline LCNS 8 & $\begin{array}{l}\text { Ina team with three other LCNS in large NHS } \\
\text { Hospital Trust in a city. Just awarded funding } \\
\text { for additional LCNS post. In post } 14 \text { years. }\end{array}$ \\
\hline LCNS 9 & $\begin{array}{l}\text { Single-handed LCNS in an NHS Hospital Trust } \\
\text { serving rural area. In post } 10 \text { years. }\end{array}$ \\
\hline LCNS 10 & $\begin{array}{l}\text { LCNS in an NHS Hospital Trust serving rural/ } \\
\text { town area. In post } 17 \text { years. }\end{array}$ \\
\hline LCNS 11 & $\begin{array}{l}\text { LCNS in large city NHS Teaching Hospital } \\
\text { Trust in a team of } 1.5 \text { LCNSs. Works with } \\
\text { one additional half time LCNS. In post } \\
\text { approximately } 5 \text { years. }\end{array}$ \\
\hline LCNS 12 & $\begin{array}{l}\text { LCNS in large city NHS Teaching Hospital } \\
\text { Trust in a team with two other LCNSs. In post } \\
13 \text { years. }\end{array}$ \\
\hline LCNS 13 & $\begin{array}{l}\text { LCNS in large city NHS Teaching Hospital } \\
\text { Trust. Trust covers two sites. LCNS } 13 \text { covers } \\
\text { one site. In post } 18 \text { years. }\end{array}$ \\
\hline LCNS 14 & $\begin{array}{l}\text { LCNS in large NHS Teaching Hospital in a } \\
\text { team of } 3 \text { LCNSs. Been in post }>20 \text { years. }\end{array}$ \\
\hline D 1 & $\begin{array}{l}\text { Respiratory consultant in NHS Teaching } \\
\text { Hospital Trust. }<3 \text { years in post. }\end{array}$ \\
\hline SW 1 & $\begin{array}{l}\text { A support worker in a team of three LCNS in } \\
\text { an NHS Hospital Trust serving rural/town area. } \\
\text { In post }<3 \text { years. }\end{array}$ \\
\hline
\end{tabular}

LCNS, lung cancer nurse specialist; NHS, National Health Service; RADIO Meso, Receiving A Diagnosis Of Mesothelioma.

the development of recommendations. The recommendation development required participation of people with a degree of expertise. Two group interviews with 42 participants were held adjacent to pre-existing meetings and events. One group $(\mathrm{n}=27)$ was scheduled within a patients and carers day organised by Mesothelioma UK. The other group was arranged within a UK Mesothelioma CNS meeting $(\mathrm{n}=15)$. Participants were informed about the study and the group interview event when they were provided with information about the event or meeting. Those who were interested attended the group interview and consent was obtained prior to this commencing.

\section{Consultation}

All individual interview participants were contacted to comment on the recommendations as part of the consultation. Seven responses were obtained from the interview participants (one daughter, one wife, one patient, three CNSs and one doctor). In addition, members and users of Mesothelioma UK (service users) were asked to participate in the consultation. In all, 32 Mesothelioma UK service users provided responses.

\section{Data collection}

Data collection took place between March 2017 and April 2018.

\section{Individual Interviews}

Individual interviews were conducted over the telephone, following informed consent being obtained. Topic guides were developed following engagement with the available literature and consultation with both the advisory group and Patient and Public Involvement representatives. The topic guide contained questions on experiences of diagnostic communication, including prognosis, treatment and legal/financial implications (see box 1 for more detail).

\section{Group interviews}

Group interview participants were asked to share their experiences of communicating a mesothelioma diagnosis, particularly positive experiences as well as concerns. Participants recorded their thoughts in brief notes, which were used to guide the discussion and were later collected and collated. Participants also proposed recommendations for best practice regarding mesothelioma diagnostic communication. Notes were taken by a member of the research team throughout the event to record the discussion.

\section{Consultation methods}

The national consultation was held between March and April 2018, inviting comments on the draft recommendations. An electronic survey was shared via email and through various social media platforms, including the Mesothelioma UK online newsletter and website.

\section{Data handling and analysis}

All individual interviews were digitally recorded with the participants' consent and the data were transcribed in full. Any identifying data were removed and the anonymised data were entered into QUIRKOS, a qualitative analysis software. QUIRKOS was used to store, manage and search the data. Data from the group interviews were also transcribed and uploaded into QUIRKOS for analysis. 
Box 1. Initial topic guide for individual interviews with patients and family carers.

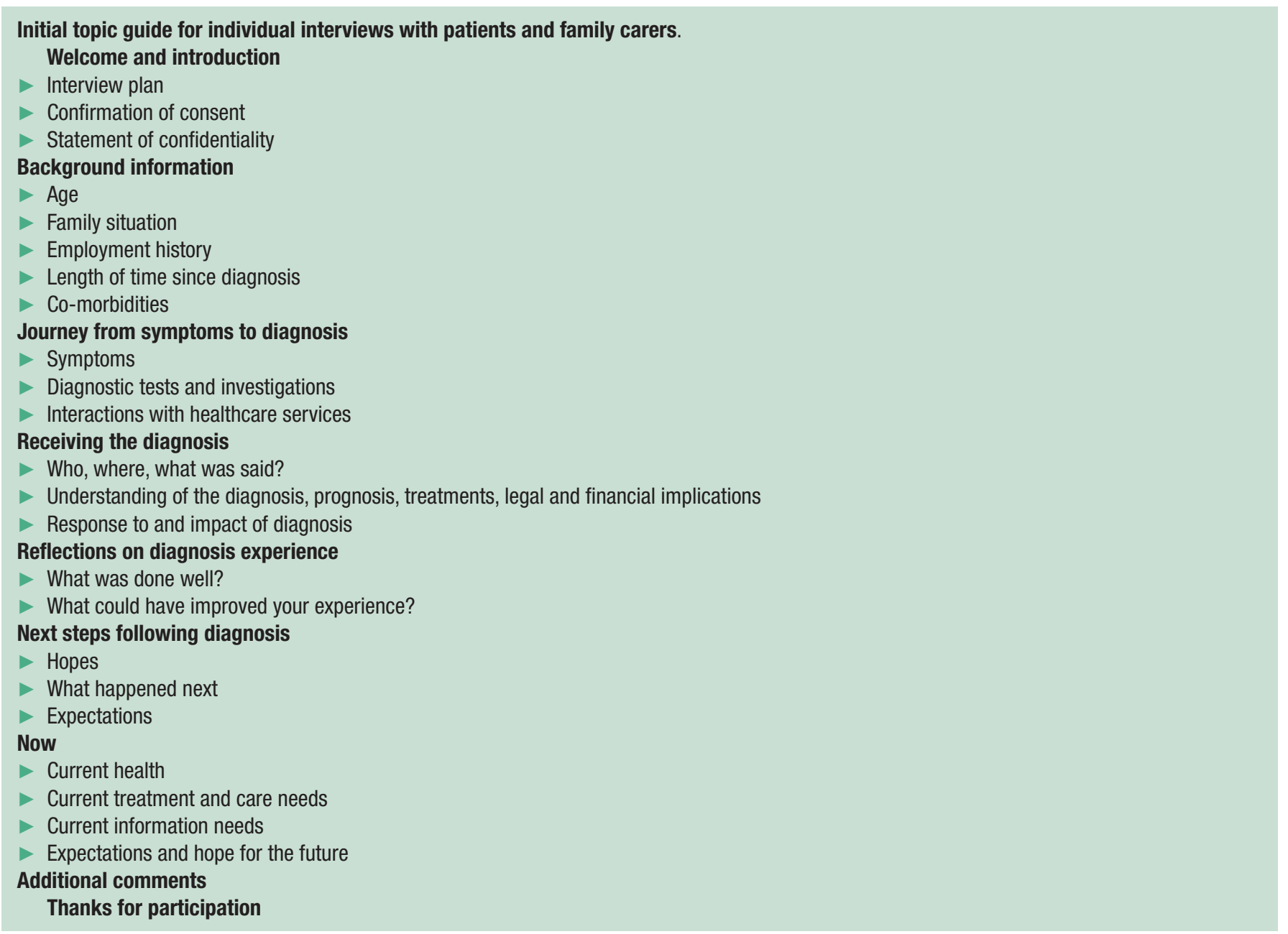

Framework analysis was used throughout to interpret the data and identify key themes and issues relating to the diagnostic experience. ${ }^{12}$ The five stages of framework analysis (familiarisation, developing a thematic framework, indexing, charting, and mapping and interpretation) were followed. This study was iterative in nature. Each stage built on the previous one, as demonstrated by figure 1 . After the individual interviews, a provisional thematic framework was developed. This framework was revised following each stage of data collection. All data were analysed by two researchers (BT and AT). Following each stage, interpretations of the data were discussed and consensus achieved through discussion with the third researcher (CW). Having three stages of data collection and analysis (individual and group interviews and a consultation) helped to verify findings through triangulation of methods. It also helped ensure saturation was achieved, that no new themes were emerging from the data.

Written informed consent was obtained from all participants. The study was approved by The University of Sheffield Research Ethics Committee.

\section{RESULTS}

An overview of the collated findings from all stages of the study are presented here, using the main themes as subheadings. These themes provided the basis for the recommendations that were summarised in an accessible document for health professionals (see figure 2). ${ }^{13}$

\section{Impact of diagnosis}

Underpinning all the results are the shock and devastation that all patients and family carers reported on being informed about the mesothelioma diagnosis (See box 2). For some participants, their reaction meant that they were unable to take in any additional information during the consultation and this had an impact on their subsequent information and support needs.

\section{Continuity and consistency}

For many people, the road to diagnosis was long, and involved distressing symptoms and worrying periods of uncertainty as they went through the process of diagnostic tests and consultations (box 3). This finding supports the 


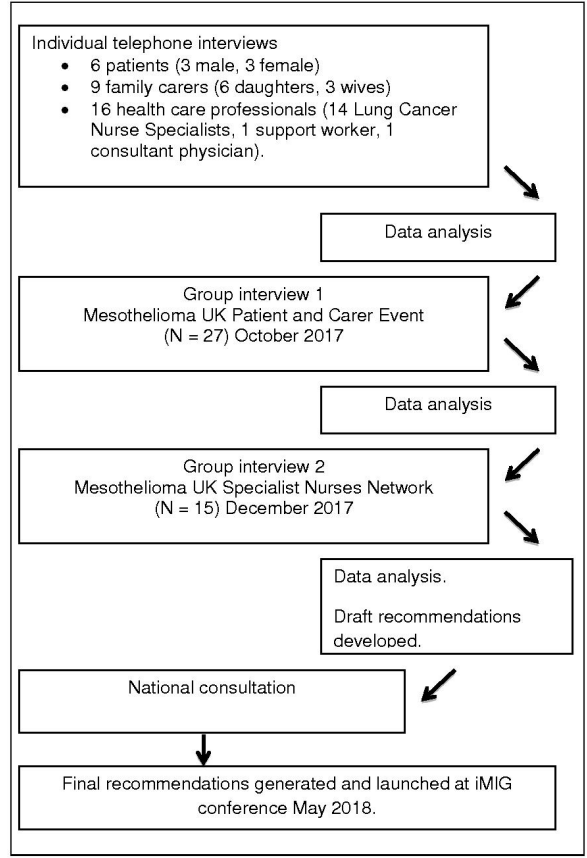

Figure 1 RADIO Meso data generation and analysis. iMIG, International Mesothelioma Interest Group; RADIO Meso, Receiving A Diagnosis Of Mesothelioma.

proposal that should be seen as a process, not a moment in time. Ensuring continuity and consistency in terms of what is said by whom emerged as a key factor in providing good quality communication and care.

When pathways broke down, communication also became fractured. This had a distressing impact on patients and families. For example, when there was a delay in processing and communicating diagnostic test results, participant's anxiety understandably increased.

\section{The role of the CNS}

The continuity provided by a LCNS being accessible to patients throughout the diagnostic pathway was reported to improve the quality of the diagnosis experience (box 4). The LCNS was seen as being able to facilitate communication across the diagnostic pathway and between the multidisciplinary team (MDT) members. They explained what was happening and why, regarding diagnostic procedures, tests and appointments and tracked progress through these over the pathway. Participants highlighted that, if the impact of the LCNS is to be realised, local systems should ensure the CNS is informed as soon as a mesothelioma diagnosis is suspected, whether the person is an inpatient or outpatient.

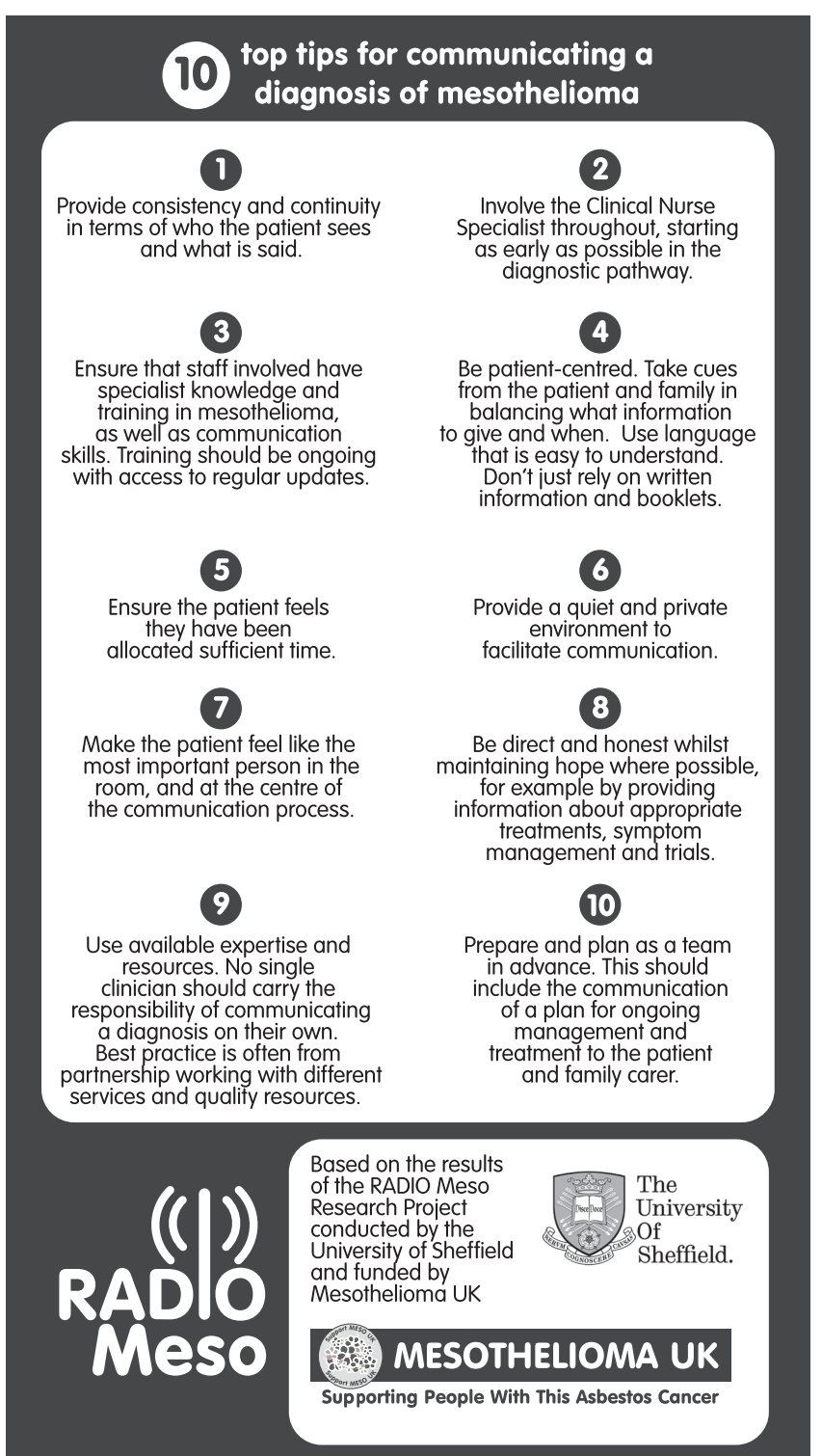

Figure 210 top tips for communicating a diagnosis of mesothelioma.

\section{Specialist knowledge and training in mesothelioma and communication skills}

Having specialist mesothelioma knowledge emerged as vital in enabling staff to clearly explain essential information related to diagnosis including the condition, pending procedures, legal and financial implications, as well as treatment and clinical trial options (box 5).

Patients and carers explained that the way information was communicated was as important as the words used. Communication skills valued by participants in this study

\section{Box 2. Impact of diagnosis}

"I don't remember actually leaving and thinking, I don't know enough. I think, at that point... at that point, you're quite shocked and numb". (Family carer 3)

"The initial diagnosis is obviously a shock for everybody and you need a little bit of time just to discuss it or talk about it. You go away, you know nothing. You don't even know what mesothelioma is. I don't think either one of us could spell it when we left". (Patient 1) 


\section{Box 3. Continuity and consistency}

"I think the fact that he had to then wait another two or 3 weeks for those results, was really hard... because obviously, during that time, everyone's worried and you don't know what it is and you don't know what to expect, because no one had really prepared us for anything". (Family carer 3).

"I think the pre-work you do, as in what you do in that first consultation, the support you give them during the test and the results, and on the day you get the results. The ones where I feel it's very different and where we don't have an input or an impact is the inpatients... we're not aware of what they've been told or what their expectations are. You might meet them for the first time at diagnosis. That's more difficult, when you've not got that relationship, when you've not got established contact and careful communication". (LCNS 2)

"And that's really the only criticism I suppose l've got, the fact that it took so long from January to May I was being seen by different doctors and, you know, I was supposed to have this scan and that scan and it didn't happen and having to chase them up and it had been lost in wherever, you know what I mean, or whatever, so, you know, that made me, added to the anxiety I suppose really, because you know you're ill, but you don't know what's wrong with you". (Patient 3)

included the ability to communicate in a warm, inclusive, respectful and participatory manner.

Staff participants valued regular training updates to support ongoing development of mesothelioma knowledge and communications skills. Opportunities for supervision, reflection and learning from others were recommended to supplement formal training. However, there was evidence in the interviews that this was not always readily available or accessible. All the specialist nurse and medical participants had attended advanced communication training, in line with recommended practice since the 2000 National Health Service Cancer Plan. ${ }^{14}$ However, a concern was expressed about the absence of any follow-up communication training or supervision to support development and maintenance of diagnostic communication skills.

\section{Being patient-centred}

The interview data revealed that people vary tremendously in the amount of information they want to know and are able to assimilate when being given diagnostic information. Participant's descriptions of their experiences indicate that being skilled at listening, assessing what people know already, taking cues from body language and gauging people's response to information is critical in helping identify what is appropriate to say, when and how. Although some patients and carers were keen to seek lots of information, some also highlighted that there was a risk of feeling overloaded with information. Avoiding unnecessary medical terms and the use of technical language were seen as part of the process of personalising information provision (box 6).

Pathways, processes and experiences did vary across the health professionals who took part. However, all agreed that keeping the patient at the centre of services, practice and decision-making improved diagnostic communication. In short, making sure the patient feels that they are the most important person in the room, and at the centre of the communication process, was seen as a priority. If this occurs, the patient and family are more likely to access ongoing support and information to meet their needs across the diagnostic pathway.

\section{Preparation and planning}

Feeling prepared and having a plan were important for patients and carers in terms of knowing what to expect along the diagnostic pathway (box 7). Participant's experiences indicated how important it was for the healthcare team to be prepared prior to providing information about their diagnosis, including having a clear plan to present to the patient regarding the next steps. However, there were examples from all participant groups indicating that planning could be difficult due to the reality and constraints of everyday practice. Having good multi-disciplinary working relationships where everyone plays to their strengths is an advantage. Specialist MDTs were identified as positive examples of teamwork and instrumental in ensuring patients had a clear and appropriate plan, including access to relevant clinical trials.

\section{Environment}

The importance of a quiet and private environment to facilitate communication was emphasised by patients and carers (box 8). However, many staff reported difficulties in achieving this due to the pressure on limited clinic space.

Strategies that were utilised by healthcare participants included using magnets or curtain clips to signify that a conversation should not be disturbed in inpatient areas and scheduling BBN appointments at the end of clinic when there is more privacy and less noise.

\section{Box 4. The role of the clinical nurse specialist}

"And I do think as a nurse, especially because we get to know the patients as a person, not an illness, and I think it's our role to be their advocate and to fight their corner". (LCNS 7 )

"The most expert form of contact was the specialist meso nurse. And I knew that she would be there, she told me, she'd be on the phone, and I could ring her anytime". (Family carer 4) 


\section{Box 5. Knowledge and training}

"I mean her body language was very good; you know, she faced us head on, she didn't look away, it was eye to eye contact. The Specialist Nurse was in the room with us as well, and they were behind us with their hand on our shoulders. It was the best it could have been, if you know what I mean". (Family carer 8)

"I had personal clinical supervision, which I pay privately for, because I was recognising in this job you need to have someone to talk to .... There was talk about the advanced communication skills training was going to be kind of every 3 years, to be an update day, but that never happened, which is a real shame, because I think that would have been invaluable". (LCNS 7$)$

"The only other thing is... some of our more junior... we had a more junior consultant, I would say, who seemed less familiar with mesothelioma and she... and the way she explained it to the patient, was that it was a mass. She explained it more like a tumour, rather than exactly what's going on in this poor patient's body. That caused... that really caused quite a lot of concern and a lot of conflict in the patient's mind. That took a lot of unpicking. So, I think, because in our Trust, the consultants aren't meeting that many patients, I think their knowledge sometimes isn't as good as it can be. That's something that I think... if I could, I would ensure that the consultants knew a lot more about it". (LCNS 9 )

\section{Time}

Allocating appropriate time was seen as essential to good communication of a mesothelioma diagnosis. There were so many aspects to the diagnosis, and the impact was so profound that all participants recognised the appointment could not be rushed. Participants also described how creating a sense of time was important, for example, by listening, being patient-centred and not going through information like a checklist (box 9).

\section{Honesty}

Many participants described how they considered it important for health professionals to achieve a balance between providing upsetting news with positives. The majority of patients said they preferred information to be given in a direct and honest way while maintaining hope at the same time (box 10).

Good effective MDT working was seen to be helpful in maintaining hope. Patients and families reported that knowing the MDT, a room of experts, had reviewed the patient's case provided them with confidence related to the diagnosis, treatment plans and access to clinical trials.

\section{Available expertise and resources}

Participants' accounts and experience indicated that no single clinician should carry the responsibility of communicating a diagnosis alone. There are a range of practitioners and services, with varied expertise, that staff can refer to throughout the diagnostic process in order to aid the patient and carer experience (box 11). For example, Asbestos Advisory Services/Groups are often best placed to advise on benefits, compensation and legal claims. Resources from specialist organisations can be shared with patients to ensure up-to-date and good quality, accessible information and support. Examples include the information resources and telephone helpline developed and delivered by Mesothelioma UK.

\section{DISCUSSION}

\section{Summary of key findings}

This study provides unique insight into the experience of patients, family carers and health professionals regarding a mesothelioma diagnosis. The complexity of receiving a mesothelioma diagnosis and the devastating impact of this have been reported elsewhere. ${ }^{3-6}$ A key finding was the importance of regarding communicating a diagnosis as a process, rather than one episode of care. Providing continuity and consistency across that process in terms of what is said by whom was vital. The findings from this study highlight the importance of the LCNS in providing continuity and consistency prior to diagnostic confirmation and following on from this. The recent National Mesothelioma Audit Report ${ }^{15}$ indicated that $93 \%$ of patients in Wales had access to a CNS. In contrast, CNS access in England was seen to vary by network from $28 \%$ to $62 \%$. Although data completion for this item was low (66\%), this audit finding raises questions regarding access to CNS support, advice and care, especially when RADIO Meso illustrates how vital the role is for patient experience and diagnostic communication.

RADIO Meso also identified that providing consultation time and a conducive environment are fundamental

\section{Box 6. Being patient-centred}

So she was able to explain a lot of it and she used drawings and pictures and things to show me because I hadn't even got a clue, I didn't know anything about lungs. (Family carer 6 )

We are very much guided by what they want. So you're sat in that room with a relative usually, or two, and the patient. They usually all want to know varying degrees of information, from the thread to the needle. Some wanting to include prognosis, some not. And I think that's the skill of our job, if there is a skill, which we need to very much gauge it to that audience (LCNS 2)

It's an honour almost... sounds a bit corny, but it's an honour to do it. It's a very important time in that patient's life and their families and they're never going to forget it, and you can actually change the way they feel about things. You can make a difference, hopefully, a little bit of a difference that makes things a tiny bit easier for them. You just hope that that's the difference you make. (LCNS 2) 


\section{Box 7. Preparation and planning}

One of the big things that were missing was communication between all the services, effective communication..... It was my mum phoning the doctor who initiated everything else, but by that time it was almost too late. It was like everything was being rushed. And my biggest criticism is that there should have been a plan right up front that my mum and dad should have been involved in. (Family carer 9 )

We've got excellent consultants that are really good at breaking bad news. So in the past we've had consultants that haven't been good at breaking bad news and that is what makes the difference. It's how that's done. Because that person's life is changing forever, and how that is portrayed to them is so important. So I think we are very lucky in that. We don't have to pick the pieces up from bad communication, which I have done in the past, but we don't anymore. We've got a really good team. (LCNS 3)

It (specialist mesothelioma MDT) will help with the quality of discussion around the management plan. (D 1)

We should be pushing for (trials) but unless we have these MDTs nationally to pool the patients into them then that will be a good way of getting recruitment up. (LCNS 1)

elements to good practice. This is essential for the appointment when a diagnosis is confirmed but also for those key clinical encounters before and after the mesothelioma confirmation. Staff interview data indicated that access to specialist mesothelioma information for patients and family aided the diagnostic experience. This was enhanced when staff had specialist training in mesothelioma and communication. The lack of access to follow-up training on communication and mesothelioma to emerge from the RADIO Meso findings is a concern.

Good MDT team working and discussion of patient cases at an MDT, preferably a specialist mesothelioma MDT, were reported to enhance BBN communication. ${ }^{14}$ It also helped to instil and maintain hope for patients and families following the diagnosis because it was seen to streamline access to treatment and trails. The National Mesothelioma Audit for England and Wales indicates $81 \%$ of patients were discussed by an MDT, which, while positive, did not meet the audit target of $90 \%$. In addition, there was variation in MDT discussion by network with access ranging from $53 \%$ to $100 \%$. Such variations need to be addressed if diagnostic and treatment experience is to be enhanced. The contribution of the MDT in supporting coping and maintaining hope is a new finding.

The findings illustrate how a person-centred approach and putting the patient in the centre of diagnostic care and communication decisions can have a positive impact on patient experience. RADIO Meso shows how tailoring communication to the individual's needs is vital. Fundamental to this is the patient feeling that they are at the centre of the communication process. This, and allocating sufficient time for diagnosis discussions, can be challenging within the very real pressures of clinical services.

The recommendations focus on communicating a diagnosis but it is important to remember that bad news can be broken at many points along the diagnostic and care pathway. For example, if a patient is informed that they are not eligible for a particular treatment or research trial that they had invested hope in. The recommendations may apply to communication at all points that bad news is broken.

\section{Strengths and weaknesses of the study}

RADIO Meso was successful in generating new, in-depth insight into the mesothelioma diagnosis experience. Integrating patient, family carer and staff experiences added to the richness of the insight generated. The use of layered methods of individual and group interviews plus consultation added to the rigour and strength of the study. Reliability and quality were ensured by a number of strategies including, digitally recording and transcribing interviews, checking and verification of transcripts, and analysis of data by at least two researchers. Review of coded transcripts across the research team

\section{Box 8. Environment}

We aren't well resourced, but we do insist that we have a room at the clinic. We have to battle when we go into the clinic to get a room, but we do insist that we have that room. But it isn't well resourced, to be honest. It's a bit of a battle before the clinic starts. (LCNS 4)

But we were just took in a small little room, I don't even think there was enough chairs for us to sit on, and told it's mesothelioma, which we couldn't even say, let alone know what it was. (Family carer 1)

\section{Box 9. Time}

I felt that there was a lot more that could have been done at that initial time .... you're really left to go away and wait for an appointment. Certainly (I would have liked) a longer appointment. (Patient 1)

My mum and dad were in complete shock... But I think they were in such a state that they didn't take a lot in and that was part of the problem, we think that that maybe happened too quickly. (Family carer 6) 


\section{Box 10. Honesty}

She didn't say 'you've got this and that's it'. She said 'you've got this and this is the options, from radical surgery, there is chemotherapy ... So even though it was disastrous news in many respects, she gave us a list of things that, you know, like there was a plan around what would happen, as opposed to 'you've got a terminal illness' and that's it. You know, there was a plan. (Family carer 8)

\section{Box 11. Expertise and resources}

So, the lung cancer nurse, she was really good, she got me in touch with (Asbestos Support Charity)... and they helped with filling out some DHSS forms, and things and that. (Family carer 5)

The specialist nurse took my wife into the office and sat her down, and she was obviously very upset. She gave her advice on where she could gain counselling and so on. She was very good. (Patient 6)

and discussion regarding interpretation helped generate consensus regarding the findings.

The sample did have limitations, including the fact that only one doctor volunteered to participate. These data were still included as it did add to the range of experience, along with a support worker who worked alongside a LCNS. We aimed to recruit a sample that reflected a range of settings, service size, health professional experience and patient demographic. While the sample was small, this aim was achieved and provided in-depth data from varied perspectives. We could have recruited patients through health professional participants. However, different routes of recruitment were used to remove the potential risk of data being overly influenced by the specific patient/health professional participants relationships. For example, we wanted to know about patients experiences of receiving a diagnosis of mesothelioma, not the patients experiences of care by a specific individual nurse participant.

It was not the purpose of the study to generate statistical data, but to provide understanding of the range of experiences of and influences on mesothelioma diagnosis communication. The study achieved this aim; however, caution is required regarding generalisable claims. The findings do resonate with other research regarding BBN and diagnosis communication, which does support the transferability of the findings.

\section{Comparison with other data}

RADIO Meso findings reinforce those of Warnock $e t a l^{10}$ in viewing $\mathrm{BBN}$ as a process. The studies also both indicate the complexity and challenges in BBN in such situations as a mesothelioma diagnosis. Warnock et $a l^{10}$ propose a framework of factors that influence the ability to break bad news including factors relating to situation, organisation, individual and patient/relatives. This framework has been supported by the findings presented here.

The importance of staff training and attitudes in successful BBN has been identified elsewhere. ${ }^{16}{ }^{17}$ The 3-day advanced communication training recommended to staff working in UK cancer services has been shown to increase staff confidence and ability. ${ }^{16}$ RADIO Meso emphasises the importance of refreshing and updating this training.

The challenge of being honest in communication, while maintaining patient and family hope, was highlighted by Lelorain et al. ${ }^{17}$ Similarly, RADIO Meso recognises and illustrates this challenge and factors that support it, such as access to the specialist nurse, clinical trials and new treatments and consistent communication. Getting the timing of communication right for individual patients also emerged as important in both studies.

The contribution of the CNS to improved quality of care and communication across the patient pathway has been noted elsewhere, including the field of lung cancer. ${ }^{1819}$ This study adds to that evidence and articulates the impact of the CNS on effective communication of a mesothelioma diagnosis.

\section{Implications of our findings}

The RADIO Meso study findings have huge potential to influence care and communication related to mesothelioma diagnosis communication. To facilitate this, the study team have worked with Mesothelioma UK to develop recommendations regarding mesothelioma diagnosis communication (See figure 2 for these 10 top tips). ${ }^{13}$ These are aspirational in nature and are intended to support healthcare workers' practice with individual patients. However, they can also help teams to lobby for adequate resources to support diagnosis and care, including access to a specialist mesothelioma MDT, CNS expertise or appropriate time and environments. The recommendations proposed here for mesothelioma may well apply in other conditions and settings.

The findings illustrate the complexity of communicating a diagnosis and indicate the need for further research to better understand what helps and hinders this process.

Acknowledgements We thank all the participants of the study for their time and generosity in sharing their experiences. We also thank Mesothelioma UK, NLCFN and BTOG for their support for the study generally and help in recruiting participants. We are particularly grateful to Liz Darlison, Lorraine Creech and Helena Stanley (Mesothelioma UK), Vanessa Beattie and Tricia Bryant (NLCFN), 
Dawn Mackindley (BTOG), and Simon Gribbon and Lisa Smith from (Sandstar Communications)

Contributors AT and CW had the original idea for the study. All authors contributed to the study design. BT and AT conducted the interviews. All authors participated in the analysis which was led by BT. All authors contributed and commented critically to the paper.

Funding Mesothelioma UK, (Meso1).

Competing interests None declared.

Patient consent for publication Not required.

Ethics approval Research Ethics Committee approval was obtained from the University of Sheffield.

Provenance and peer review Not commissioned; externally peer reviewed.

Data sharing statement Our primary data is available upon request.

Open access This is an open access article distributed in accordance with the Creative Commons Attribution Non Commercial (CC BY-NC 4.0) license, which permits others to distribute, remix, adapt, build upon this work non-commercially, and license their derivative works on different terms, provided the original work is properly cited, appropriate credit is given, any changes made indicated, and the use is non-commercial. See: http://creativecommons.org/licenses/by-nc/4.0/.

\section{REFERENCES}

1. Cancer Research UK. Mesothelioma incidence statistics. Available: https://www.cancerresearchuk.org/health-professional/cancerstatistics/statistics-by-cancer-type/mesothelioma/incidence [Accessed November 2018].

2. Royal College of Physicians. National mesothelioma audit report 2018 (for the audit period 2014-16. London: Royal College of Physicians, 2018. (Accessed January 2019).

3. Ball H, Moore S, Leary A. A systematic literature review comparing the psychological care needs of patients with mesothelioma and advanced lung cancer. Eur J Oncol Nurs 2016;25:62-7.

4. Guglielmucci F, Bonafede M, Franzoi IG, et al. Research and malignant mesothelioma: lines of action for clinical psychology. Annali dell'Istituto Superiore Di Sanit2018;54:149-59.
5. Hughes N, Arber A. The lived experience of patients with pleural mesothelioma. International Journal of Palliative Nursing 2008;14:66-71.

6. Clayson H, Seymour J, Noble B. Mesothelioma from the patient's perspective. Hematology/Oncology Clinics of North America 2005;19:1175-90.

7. Ewing G, Ngwenya N, Bensonb J, et al. Sharing news of lung cancer diagnosis with adult family members and friends. Patient Educ Couns 2016:99:378-85

8. Warnock C, Tod AM, Foster J, et al. Breaking bad news in inpatient clinical settings: role of the nurse. J Adv Nurs 2010.

9. Fallowfield L, Jenkins V. Communicating sad, bad, and difficult news in medicine. The Lancet 2004;363:312-9.

10. Warnock $\mathrm{C}$. Breaking bad news: issues relating to nursing practice. Nursing Standard 2014;28:51-8.

11. Warnock C, Buchanan J, Tod AM. The difficulties experienced by nurses and healthcare staff involved in the process of breaking bad news. J Adv Nurs 2017;73:1632-45.

12. Ritchie J, Lewis J, McNaughton Nicholls C, et al. Qualitative research practice. London: Sage, 2013.

13. Mesothelioma UK. 10 top tips for communicating a diagnosis of mesothelioma. Available: https://www.mesothelioma.uk.com/news/ radio-meso-study-publishes-results/ [Accessed November 2018]

14. Department of Health. The NHS cancer plan. London: Department of Health, 2000

15. Royal College of Physicians. National mesothelioma audit report, 2018(for the audit period 2014-16)

16. Wilkinson S, Perry R, Blanchard K, et al. Effectiveness of a three-day communication skills course in changing nurses' communication skills with cancer/palliative care patients: a randomised controlled trial. Palliat Med 2008;22:365-75.

17. Lelorain $\mathrm{S}$, Cortot $\mathrm{A}$, Christophe V, et al. Physician empathy interacts with breaking bad news in predicting lung cancer and pleural mesothelioma patient survival: timing may be crucial. Journal of Clinical Medicine 2018;7.

18. Tod AM, Redman J, McDonnell A, et al. Increasing access to lung cancer treatment: the role of the lung cancer nurse specialist. BMJ Open 2015;5:e008587.

19. Health Service Journal Time for some advanced thinking: the benefits of advanced nursing?Available: https://www.hsj.co.uk/ Uploads/2015/02/25/f/c/y/HSJ-Workforce-Supplement-150227.pdf [Accessed February 2019]. 